\title{
A integração da TIC na Escola
}

\section{Básica: Questões para Avaliação}

\author{
Ana Maria Severiano de Paiva \\ Docente do Programa de Mestrado Profissional \\ em \\ Educação Matemática \\ Universidade Severino Sombra \\ anaseveriano@uol.com.br \\ Carlos Vitor de A. Carvalho \\ Docente do Programa de Mestrado Profissional \\ em \\ Educação Matemática \\ Universidade Severino Sombra \\ cvitorc@gmail.com
}

\author{
Janaina Veiga Carvalho \\ Docente do Programa de Mestrado Profissional \\ em \\ Educação Matemática \\ Universidade Severino Sombra \\ janainavcarvalho@gmail.com \\ Irlaine da Paixão Gomes Porto \\ Discente do Curso de Especialização em \\ Educação \\ Matemática \\ Universidade Severino Sombra \\ rlapaixao@gmail.com
}

\begin{abstract}
Resumo Este trabalho discute a integração das tecnologias de informação e comunicação em escolas de educação básica e nível médio, do Estado do Rio de Janeiro. O artigo aponta algumas dimensões dessa questão articulada aos objetivos do Plano de Desenvolvimento da Educação $(P D E)$ e de uma das suas ações, o Programa Nacional de Tecnologia Educacional (ProInfo) como a problemática da formação de professores, da instituição escolar e da prática pedagógica. Insere-se este trabalho na articulação das linhas de pesquisa do Programa de PósGraduação - Mestrado Profissional em Educação Matemática da Universidade Severino Sombra (USS): a) Metodologias e tecnologias de informação aplicadas ao ensino de matemática; b) Organização curricular em matemática e formação de professores. Refletimos sobre a temática a partir da perspectiva crítico-reflexiva sobre Formação de Professores, colocando em questão os locais dessa formação, os cursos de licenciatura e a escola básica através de uma questão fundamental: como estamos formando professores?
\end{abstract}

Palavras-Chave: Políticas Públicas - Práticas Pedagógicas- Tecnologias de Informação e Comunicação.

\begin{abstract}
This work talk about the integration of Communication and Information Technology in basic education, media level, Schools of States to Rio de Janeiro. The article aims some dimensions of that subject articulated to the objectives of the Plan of Education Development (PDE) and one of its action: National Program of Educational Technology (ProInfo) as: the problem of the teachers' formation, of the school institution and of the pedagogic practice. This work is inserted in the articulation of the researcher's lines of the Pos-Graduate Program, Professional Masters of Mathematics Education, Severino Sombra University (USS): a) Methodology and information technology applied on mathematics learning. We think about the thematic perspective reflexivecritical teachers' formation, putting in subject the place this formation, the teaching courses and the basic schools between of the fundamental subject: How are we fomented the teachers?
\end{abstract}

Keywords: Public Politics- Pedagogic Practices - Communication and Information Technology 
Ana Maria Severiano de Paiva,

Janaina Veiga Carvalho,

Carlos Vitor de Alencar Carvalho

Irlaine da Paixão Gomes Porto

A integração da TIC na Escola Básica: Questões para Avaliação

\section{Introdução}

O Programa Nacional de Tecnologia Educacional (ProInfo), executado no âmbito do Ministério da Educação, promoverá o uso pedagógico das tecnologias de informação e comunicação nas redes públicas de educação básica. O decreto $\mathrm{n}^{\circ}$. 6.300, de 12 de dezembro de 2007, [1] define no art. $1^{\circ}$ uma das ações do Plano de Desenvolvimento da Educação (PDE) [2]. Neste há a afirmação de que se pretende, através dessas ações, "enfrentar estruturalmente a desigualdade de oportunidades educacionais". Pelo ProInfo, como se observa nos objetivos previstos no art. $1^{\circ}$, pretende o PDE "contribuir com a inclusão digital por meio da ampliação do acesso a computadores, da conexão à rede mundial de computadores e de outras tecnologias digitais, beneficiando a comunidade escolar e a população próxima às escolas". Neste sentido, observamos no estado do Rio de Janeiro, ações como as da Secretaria Estadual de Educação, de entregar a cada professor que atua no ensino Fundamental e Médio laptops com conexão à internet.

As Tecnologias de Informação e Comunicação (TIC) são as ferramentas da denominada "sociedade de informação". Mas, se em muitos setores da sociedade isto já é uma realidade, no cotidiano das instituições escolares a sua presença com uso pedagógico ainda é pouco freqüente. Ao entrarmos em uma escola, muitas vezes encontramos "Laboratórios de Informática" até certo ponto em condições de funcionamento, mas sem utilização. Investigando as condições que restringem seu uso encontramos narrativas como: "os professores não têm formação"; "não há pessoa que possa se responsabilizar pelo espaço"; "faltam recursos materiais para manutenção", dentre outras questões que vêm contribuindo para o distanciamento entre escolas e a "sociedade de informação".

$\mathrm{O}$ art. $2^{\circ}$ do decreto n. 6.300 afirma que "para cumprir as ações do ProInfo será necessário o regime de colaboração entre a União, os Estados, o Distrito Federal e os Municípios, mediante adesão". Os Estados, o Distrito Federal e os Municípios que aderirem ao ProInfo são responsáveis por:

I - prover a infra-estrutura necessária para o adequado funcionamento dos ambientes tecnológicos do Programa.

II - viabilizar e incentivar a capacitação de professores e outros agentes educacionais para a utilização pedagógica das tecnologias da informação e comunicação.

Ainda no parágrafo único a que se refere o artigo $4^{\circ}$ do decreto supracitado, identificamos que "as redes de ensino deverão contemplar o uso das tecnologias de informação e comunicação nos projetos políticopedagógicos das escolas [...]" Pressupõe o poder público que "pelo domínio das ferramentas da informática" e pelo "uso pedagógico nas escolas" se ampliarão as "chances de inclusão" não só para a comunidade escolar, mas à população próxima às escolas.

Por meio da inclusão digital, através do ProInfo, identificamos ser a forma pela qual, primeiramente o governo federal e, por adesão, os governos estaduais e municipais, os criadores das condições para que as escolas da rede básica tenham acesso às tecnologias de informação e comunicação.

A partir de duas questões, nomeadamente, a política pública do ProInfo e nossas observações, quando em visita a escolas públicas do município e do estado, desenvolvemos projeto de pesquisa com o objetivo de realizar estudo exploratório das políticas públicas e das práticas pedagógicas identificadas com TIC, especificamente no ensino da matemática.

$\mathrm{O}$ projeto se insere na articulação das linhas de pesquisa do Programa de Pós-Graduação - Mestrado Profissional em Educação Matemática, da Universidade Severino Sombra (USS), constando das seguintes diretrizes: Metodologias e tecnologias de informação aplicadas ao ensino de matemática, organização curricular em matemática e formação de professores. Como o tema é amplo propomos recorte de análise que permita-nos pensar "os modos" de implantação, acesso e uso do computador e da Internet visando investigar:

a) o que muda na organização do trabalho e na profissão docente com as tecnologias de informação e comunicação em rede, com ênfase no uso da internet.

b) como a TIC interfere na construção do conhecimento e quais as conseqüências para o processo de aprendizagem.

Observamos que a introdução das TIC na educação básica traz questões para a prática pedagógica. Desse modo, queremos refletir a partir da seguinte questão de investigação: quais serão os impactos que estas iniciativas do PDE e do ProInfo poderão trazer à prática docente e aos processos de ensino-aprendizagem da matemática no ensino médio?

No campo das práticas pedagógicas as TIC exigem mobilização de saberes pedagógicos capazes de atender demandas socioeducativas trazidas pelas transformações profundas por que passam as sociedades contemporâneas. Assim, é relevante refletir como podem ser uma fonte de 
Ana Maria Severiano de Paiva,

Janaina Veiga Carvalho,

Carlos Vitor de Alencar Carvalho

Irlaine da Paixão Gomes Porto

A integração da TIC na Escola Básica: Questões para Avaliação

apoio na construção das aprendizagens, de investigação, de informação, de comunicação, possibilitando acesso a um mundo e conhecimento globais no sentido de espaços e de tempos.

Diversos autores, entre os quais professor Ubiratan D’Ambrósio [3], aponta que as TIC geram rupturas no campo das práticas educativas instituídas e instituintes para o que sejam tempos e espaços de aprender.

Espaço e tempo são subordinados ao linear e ao quantitativo, que tem sido a sustentação dos sistemas escolares vigentes. Talvez o maior desafio conceitual na educação seja passar do linear para o complexo e do quantitativo para o qualitativo. [3]

Mas, se nos defrontamos com possibilidades, também nos defrontamos com desafios e incertezas no processo de ensino-aprendizagem da Matemática. O Professor Carlos Eduardo Mathias Motta [4], quando aborda a questão das "Novas Tecnologias no ensino da Matemática" afirma que:

[...] apesar de todos os programas governamentais, o primeiro grande desafio que teremos de enfrentar é o da capacitação docente. Qualquer recurso didático esteja ele ligado a qualquer metodologia, seja ele tecnológico ou não, dificilmente será a perdição ou a solução para qualquer questão educacional. A pergunta a ser feita é: os professores estão aptos a investigar tal recurso a ponto de correlacionar o seu potencial às suas necessidades? $\mathrm{O}$ uso das novas tecnologias no ensino da matemática exigirá dos professores a releitura crítica de suas práticas. [4]

\section{Problematizando a formação de professores}

Observamos que começa a ser colocada em prática uma nova tendência quando se pensa em Formação de Professores. Em relação a estes observamos que não são tratados como unicamente agentes que se conformam, estritamente, ao sistema normativo, mas, como aqueles que atuam na sociedade. Isto significa colocar em pauta outras lógicas que atravessam as práticas de professores. De certa forma, há um reconhecimento de que, para saber ensinar, não basta a experiência e os conhecimentos específicos, mas se tornam necessários os saberes da experiência, os saberes produzidos no cotidiano docente, através da reflexão sobre a prática.
Nóvoa [5], ao analisar a construção da identidade do professor aborda três lógicas que articulam a formação e a prática: a adesão, quando se refere a princípios e a valores; a ação quando define a escolha das melhores maneiras de agir; autoconsistência que envolve processo de reflexão durante a ação. Considerando os estudos estrangeiros que têm servido de referência para as pesquisas brasileiras destacamos os de Schön [6], com abordagem sobre a reflexão na ação quando os professores pensam o que fazem, enquanto fazem; os de Tardif [7]; os de Gauthier [8] e Zeichner [9], que considera a reflexão não como um conjunto de técnicas que possam ser empacotadas e ensinadas aos professores, não consistindo num conjunto de passos ou procedimentos específicos. Considera este autor que ser reflexivo é uma maneira de ser professor.

Todos os autores partem da idéia de que a profissão se vai construindo à medida que o professor articula o conhecimento teórico-acadêmico, a cultura escolar e a reflexão sobre a prática docente. Faz-se, então, necessária a reflexão sobre a prática em um período em que se fala em sociedade do conhecimento, sociedade em rede, sociedade da comunicação, provocando novos direcionamentos dos processos educativos e de suas práticas no interior das escolas.

Analisando-se a formação a partir de uma perspectiva crítico-reflexiva importa considerar o professor como uma pessoa. E, como afirma Nóvoa [10], uma parte importante da pessoa é o professor. Este deve apropriar-se dos seus processos de formação e dar-lhes um sentido no quadro de suas histórias de vida. A formação, nessa perspectiva de análise, não se constrói por acumulação, mas através de um trabalho de reflexão crítica sobre as práticas e de (re)construção permanente de uma identidade pessoal. Sabemos que não basta mudar o profissional; é preciso mudar também os contextos em que ele intervém.

A formação se faz durante o processo de mudança e as TIC trazem mudanças para a prática docente. O que nos parece, impõe a necessidade de repensar a formação de professores, não somente dando-lhes ferramentas como "laptops", mas principalmente transformando os espaços educativos e garantindo processos de formação continuada. Este fim é assegurado no art. $4^{\circ}$ pelo menos no texto do Decreto ${ }^{\circ} 6300$ :

III - assegurar recursos humanos e condições necessárias ao trabalho de equipes de apoio para o desenvolvimento e acompanhamento das ações de capacitação nas escolas;

IV - assegurar suporte técnico e manutenção dos 
equipamentos do ambiente tecnológico do Programa, findo o prazo de garantia da empresa fornecedora contratada.

Quando o PDE e o ProInfo têm entre seus objetivos que "as redes de ensino deverão contemplar o uso das tecnologias de informação e comunicação nos projetos político-pedagógico das escolas", uma série de questões se apresentarão relacionadas diretamente ao conjunto de transformações no modo de pensar e conviver da humanidade. Transformações no modo de pensar e conviver, quando abordadas no espaço da escola e do processo de escolarização, indicam a necessidade de discussão das práticas pedagógicas que nele se estabelecem. Para esta questão observamos o que o ProInfo considera como objetivo: "viabilizar e incentivar a capacitação de professores e outros agentes educacionais para utilização pedagógica das tecnologias da informação e comunicação".

António Nóvoa, educador português, em dois de seus livros mais importantes - Vidas de Professores (1992) e Formação de Professores (1992) - reflete sobre o processo e os locais de formação. Para este autor "não se trata de mobilizar a experiência apenas numa dimensão pedagógica, mas num quadro conceitual de produção de saberes. Por isso é importante que as redes de (auto) formação, assumirem a formação como um processo interativo e dinâmico" [10].

\section{Problematizando a instituição escolar}

No espaço da escola essas questões vêm contribuindo para rupturas nos modelos de representação da realidade exigindo de cada um de nós, professores, a indispensável problematização da prática pedagógica e da instituição escolar.

No momento em que, no contexto da globalização, há a desintegração do lugar social do Estado, surge uma reconfiguração do sistema educativo, a partir da definição do espaço social que ocupa a escola [11]. Como expressão dessa reconfiguração das relações do Estado com a sociedade, caracterizada pela descentralização, observamos que é para o interior das escolas que se dirigem e organizam as reformas $\mathrm{e}$ as políticas educacionais. A Escola vivencia um processo de reconstrução de sua identidade através de uma nova articulação com diferentes demandas e sujeitos sociais, o que the fornece centralidade quando das discussões sobre a relação do Estado com a sociedade, configurando-se como "um local de decisões".

Não há como ignorar que as mudanças na economia e no trabalho passam a exigir conhecimentos que a escola pode transmitir, não sendo mais o local simplesmente da socialização, mas de inclusão pelo acesso e ampliação de conhecimentos que possibilitem inserções social, econômica e cultural. A escola torna-se, não só para a comunidade, mas para o próprio poder público, o centro de referência das políticas públicas, identificadas com Direitos Sociais. Nessa perspectiva, a instituição escolar que aglutina identidades e interesses tem papel central, uma vez que se constitui em instância na qual, de fato, se objetiva a implementação das políticas educacionais nacionais.

Será necessário discutir essas questões através da identificação de como a sociedade mais ampla vem pensando a questão do acesso às tecnologias de informação e comunicação, em especial - o computador e a internet - associados à conquista de direitos de cidadania.

\section{Problematizando a prática pedagógica}

As pesquisas sobre tecnologias de informação e comunicação apontam para uma revisão de compreensão da prática pedagógica, com o desenvolvimento de estudos que utilizam uma abordagem teórico-metodológica que analisa as transformações ocorridas no final do século XX. Isso está a exigir e pode provocar a construção de um novo modelo pedagógico, assim como novas formas de construção de subjetividades, de relações sociais. Para tanto, a tecnologia na escola não pode ser vista apenas como instrumento ou ferramenta.

É necessário entendermos a tecnologia não apenas como o fazer, mas como o dizer, o entender, o intencionar o que se faz. Entretanto, não basta transformar somente a escola, ela é apenas um dos vários contextos com os quais interagimos [7]. Neste sentido é fundamental entendermos a educação de forma mais abrangente, para além do espaço escolar e, portanto, para o espaço da definição de políticas públicas.

O uso do computador no cotidiano permite ampliação e integração com o conhecimento e passa a ser fundamental porque "[...] integra o homem nos contextos social e cultural, como sujeito cognitivo que aprende, a partir de relações dialéticas, dentro de uma ecologia cognitiva, na qual a informação e conhecimento são, ao 
Ana Maria Severiano de Paiva,

Janaina Veiga Carvalho,

Carlos Vitor de Alencar Carvalho

Irlaine da Paixão Gomes Porto

A integração da TIC na Escola Básica: Questões para Avaliação

mesmo tempo, fonte e produto do saber" [12].

Nos Parâmetros Curriculares Nacionais (PCNs), especialmente aqueles direcionados ao Ensino Médio, encontramos a presença das tecnologias em cada uma das áreas do conhecimento, indicando a necessidade de desenvolver habilidades identificadas com as diferentes linguagens em todos os campos do saber:

[...] a opção por integrar os campos aos processos tecnológicos próprios de cada área, resulta da importância que ela adquire na educação geral - e não mais apenas na profissional. A tecnologia é o tema por excelência que permite contextualizar os conhecimentos de todas as áreas e disciplinas no mundo do trabalho. [...] não se trata apenas de dar significado ao uso da tecnologia, mas de conectar os inúmeros conhecimentos com suas aplicações tecnológicas [13].

Tecnologias mediam a prática pedagógica oferecendo desafios importantes voltados à produção intelectual, em que o aluno passa a ser produtor de conhecimento e a ação docente dá lugar à relação dialógica que permite ao professor e ao aluno aprender a aprender, num processo coletivo para a produção do conhecimento. Tanto as práticas pedagógicas quanto as TIC são práticas sociais e de comunicação. Portanto, sua articulação não pode se limitar a questões somente técnicas. Tardif [7], ao analisar a relação entre educação e TIC chama a atenção para a necessidade de implantação de políticas, o que exige uma transformação profunda, impondo, conseqüentemente, a implantação de políticas educacionais coerentes com as transformações da sociedade como um todo e não simplesmente articulados com uma perspectiva de modernização do sistema.

\section{Exemplificando o uso das TICs na escola}

Alguns exemplos do uso da TIC na escola mostram que essa prática pode e deve ser estimulada por seus professores e dirigentes. Um primeiro exemplo foi experimentação em sala de aula de um sistema computacional educacional para o apoio ao ensino de geometria plana. Trata-se do sistema TANGRAM [14]. O TANGRAM é um jogo originário da China e trazido para o Ocidente por volta da metade do século XIX. É de origem milenar, formado por apenas sete peças, com as quais é possível montar variadas figuras de animais, plantas, pessoas, objetos, entre outros.

A origem e significado da palavra Tangram têm

muitas versões. Uma delas diz que a parte final da palavra "gram" significa algo desenhado ou escrito como um diagrama. "Tan" é sinônimo de chinês. Assim, segundo essa versão, Tangram significa "quebra-cabeça chinês" [15].

O uso de jogos na aprendizagem é muito defendido por inúmeros pesquisadores, entre eles, Piaget [16], que salienta a importância desta atividade lúdica no desenvolvimento da percepção, inteligência, tendências à experimentação e sentimentos sociais da criança. $\mathrm{O}$ jogo é uma ferramenta pedagógica que favorece a concentração e atenção, desenvolve o raciocínio, possibilita a criação de estratégias e regras, trabalha com a emoção, desenvolve as capacidades indutiva, espacial, auditiva e visual, tudo de forma lúdica e prazerosa. O Software Educacional TANGRAM foi projetado e desenvolvido na Universidade Severino Sombra (USS), no âmbito de projetos de pesquisa com a participação de alunos de graduação do curso de Licenciatura em Matemática. Possui uma interface de fácil utilização interativa e o aluno tem uma participação ativa, podendo, visualizar, verificar, validar mudanças e alterações ocorridas, levando-o a construir o conhecimento.

O sistema foi utilizado com alunos do Ensino Fundamental (sexto ano) de uma escola pública.

No dia previsto para a atividade, os alunos foram levados ao laboratório de informática da escola, e foram distribuídos de forma a ficarem dois alunos por computador. Como o laboratório estava com algumas máquinas em manutenção foram utilizados apenas três computadores.

Durante a atividade foram observados o comportamento e as atitudes dos alunos diretamente com o software, permitindo, verificar que, antes de conhecer técnicas de solução de determinados problemas, o aluno pode visualizá-los e resolvê-los (Figura 1).

Foi muito interessante observar que eles demonstraram desenvoltura em relação ao uso do computador, como uma ferramenta que facilita e oferece meios muito importantes no ensino-aprendizagem, além de desenvolver a percepção visual, a habilidade e diferentes ângulos de observação. 


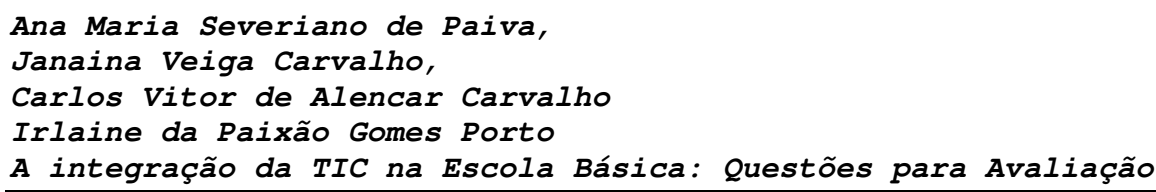

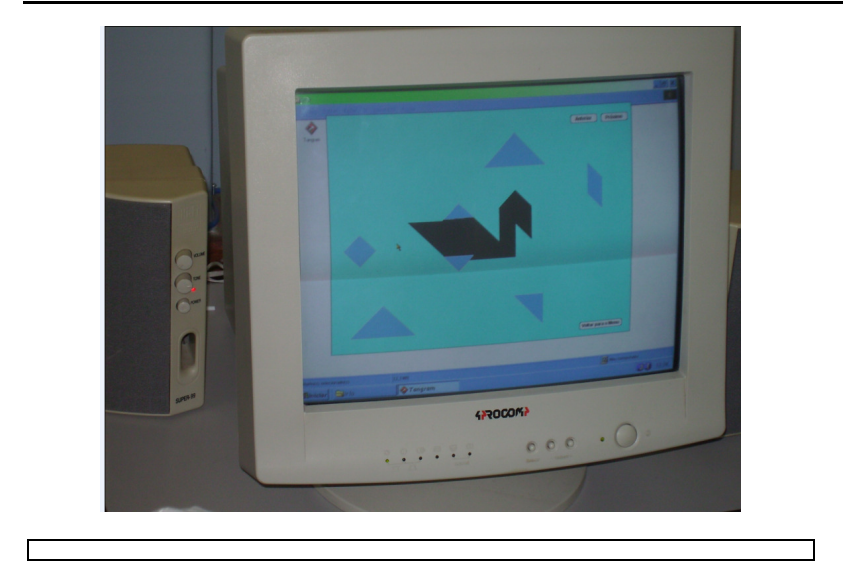

Figura 1 - Utilização por alunos em Escola do Município de Vassouras.

Um segundo exemplo foi a utilização do software CONSTRUFIG3D em oficina no laboratório de Informática durante o IV Encontro Sul-Fluminense de Educação Matemática (ESFEM), ocorrido em dezembro de 2005 na Universidade Severino Sombra (Vassouras/RJ) [17].

O CONSTRUFIG3D é um software livre e de código aberto, desenvolvido na USS, de interface bastante simples que permite a composição e visualização de figuras espaciais a partir de figuras planas selecionadas pelo aluno. Desenvolvido para alunos que estão iniciando o estudo da geometria, o CONSTRUFIG3D auxilia na identificação das figuras planas e espaciais. O sistema foi desenvolvido para ter uma grande interatividade, possibilitando aos alunos uma postura dinâmica em relação à aprendizagem e composição de figuras espaciais. Em Mendes [18] e Santos [19] podem ser encontrados outros detalhes do CONSTRUFIG3D, como o algoritmo desenvolvido para a combinação das figuras planas. O CONSTRUFIG3D pode ser obtido em [20].

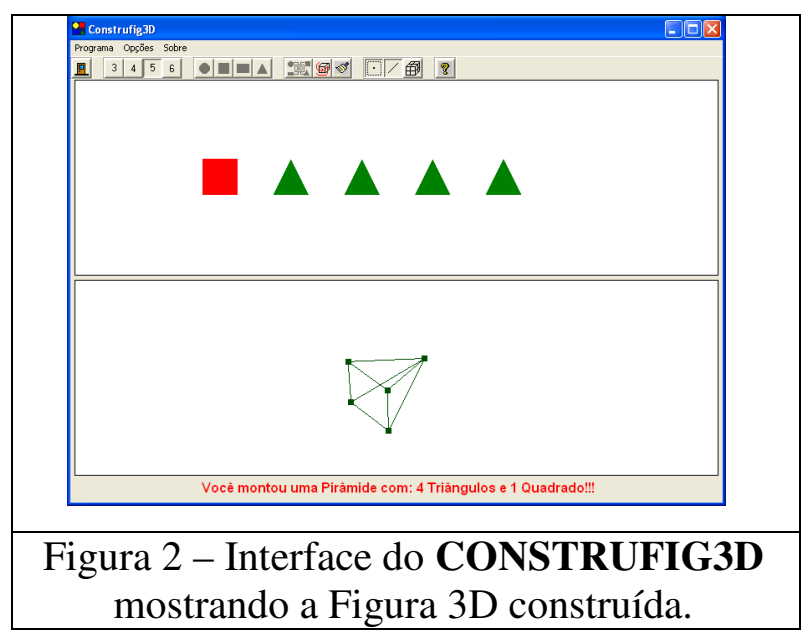

A dinâmica foi desenvolvida considerando dois momentos: o primeiro com uma atividade prática e o segundo com a utilização do CONSTRUFIG3D. A idéia principal da atividade prática é possibilitar ao aluno a manipulação e construção de figuras espaciais antes da utilização deste sistema. Assim, os alunos da oficina devem ser divididos em subgrupos (quatro integrantes em cada subgrupo, por exemplo). Cada grupo receberá um kit de montagem (4 círculos, 10 retângulos, 10 quadrados, 10 triângulos e uma fita durex). Durante vinte e cinco minutos cada subgrupo tentará montar a maior quantidade de figuras espaciais. Após esta etapa cada grupo tentará reproduzir no CONSTRUFIG3D, em 20 minutos, o processo de montagem das suas figuras espaciais.

Foi observado o entusiasmo dos alunos para montar as figuras espaciais no sistema ocorrendo até uma competição de quem montava todas as figuras em menor tempo. Os alunos gostaram muito da idéia do sistema fazendo muitos elogios. Fizeram algumas sugestões como incluir a visualização de vértices, arestas e faces (funcionalidades que já estão incorporadas na versão atual). Dois grupos identificaram uma figura espacial que não estava no sistema (o Hexaedro) e que posteriormente foi adicionada.

\section{Considerações Finais}

Tanto o PDE quanto o ProInfo ao abordarem objetivos sobre a TIC citam questões relacionadas ao direito de todos, a cidadania que, na perspectiva das políticas citadas se fariam pela inclusão, pelo acesso às tecnologias de informação e comunicação. Consideram que estas tecnologias seriam as ferramentas capazes de possibilitar e "enfrentar estruturalmente a desigualdade de oportunidades educacionais". Como o local da implantação é a escola básica, esta definida pela Lei de Diretrizes e Bases da Educação Nacional n. 9394 de 1996 como a constituída pela educação infantil, ensino fundamental e ensino médio, caberia perguntar: Como a ESCOLA pode ampliar direitos de cidadania?

Sabemos que o direito à educação de todos os homens inclui-se, hoje, na pauta das reivindicações mais significativas para a humanidade. Mais do que ir à escola é interessante ter acesso às diferentes linguagens e a diferentes saberes. É compreender o direito à educação não associado a um tempo e a um único local, mas um direito permanente e de todos.

Altera-se, a partir de então, "[...] o significado da própria noção de 'educação'. Se assumirmos que 'doravante temos de aprender durante toda a vida' e que a 
Ana Maria Severiano de Paiva,

Janaina Veiga Carvalho,

Carlos Vitor de Alencar Carvalho

Irlaine da Paixão Gomes Porto

A integração da TIC na Escola Básica: Questões para Avaliação

educação é este continuum educativo [...], então 'educação' não pode significar simplesmente "escolaridade", [21]. Educação exigirá uma análise estrutural em função de uma visão do conjunto das necessidades da sociedade. Não necessidades de mercado, mas de humanização, de solidariedade. É com o acesso à educação, pelo caminho do direito, que se colocam em cena questões como: "Há que todos têm direito, afinal?" [22].

Aprender a pensar, pesquisar, buscar informação, construir conhecimento parece ser o paradigma para aquele que deseja ir além dos registros do livro didático, que quer percorrer outras fontes de conhecimento, em uma dimensão temporal que ultrapassa o prédio escolar e as redes sociais mais próximas. Portanto, "Educar para o presente milênio significa educar com o auxílio de recursos tecnológicos e com um olhar crítico sobre aquilo que estes recursos nos estão proporcionando. $\mathrm{O}$ importante é o que faremos com a tecnologia que nos chega às mãos" [23]. É também sobre isto que o professor Carlos Eduardo Mathias Motta problematiza quando reflete sobre Novas Tecnologias no ensino da Matemática: "O uso das novas tecnologias no ensino da matemática exigirá dos professores a releitura crítica de suas práticas. Sem essa releitura, o uso das novas tecnologias terá conseqüências mais devastadoras do que construtivas" [4].

\section{Referências}

[1] BRASIL. Ministério da Educação. Decreto no. 6300, de 12 de dezembro de 2007. Disponível em http://www.planalto.gov.br/ccivil, $20 \mathrm{de}$ maio de 2008.

[2] BRASIL. Ministério da Educação. Plano de Desenvolvimento da Educação: razões, princípios e programas. (2007) Disponível em http:www.mec.gov.br, 10 de maio de 2008

D' AMBRÓSIO, Ubiratan. EDUCAÇÃ̃O NA IDADE MÍDIA: A RECONFIGURAÇÃ̃O DA ESCOLA NO ESPAÇO URBANO. Disponível

http://www rio.rj.gov.br/sme/destaque/debates. ht m. Capturado em 22/02/2006:4.

[4] MOTTA, Carlos Eduardo Mathias. Novas Tecnologias no Ensino da Matemática. Universidade Aberta do Brasil, 2008:2,3.

[5] NÓVOA, Antônio (org.). Vidas de Professores.
Porto: Porto Editora, 2000.

[6] SCHÖN, D.A. La Formación de profesionales reflexivos. Madrid: Paidós, 1992.

[7] TARDIF, Maurice; MUKAMURERA, Joséphine. La pédagogie scolaire et lês TIC: l' enseignement comme interactions, communication et pouvoirs. In Lês technologies de l' information et de la communication et leur avenir em éducation. Vol. XXVII, n.2. Disponível em http://www.acelf.ca/c/revue/revulhtml. Capturado em 27/02/2006.

[8] GAUTHIER, $\mathrm{C}$ et alli. Por Uma Teoria da Pedagogia (Pesquisas contemporâneas sobre o Saber Docente). Ijuí, Rio Grande do Sul: UNIJUÍ, 1998.

[9] ZEICHNER, Ken. Novos caminhos para o practicum: uma perspectiva para os anos 90 in NÒVOA, ANTÓNIO. Os Professores e a sua formação. Lisboa: Instituto de Inovação Educacional, 1992, p. 115-138

[10] NÓVOA, António. Os Professores e a sua formação. Lisboa: Instituto de Inovação Educacional, 1992:25:26.

[11] TIRAMONTI, Guillermina. Los Imperativos de lãs políticas educativas de los 90 . Revista da Faculdade de Educação, São Paulo: USP, v. 23, n. 1-2, jan.-dez. 1997. Disponível em http://www.scielo.gov.br em 27/02/2006

[12] COSTA, José Wilson, Maria Auxiliadora M. Oliveira. Novas linguagens e novas tecnologias. Petrópolis, RJ: Vozes, 2004:22.

[13] BRASIL. Ministério da Educação. Parâmetros curriculares nacionais para o ensino médio. Brasília, DF: MEC, SEMTEC, 2002, A, 106.

[14] PORTO, Irlaine da Paixão G. CARVALHO, C. V. A., OLIVEIRA, R., O jogo Camputacional TANGRAM: um objeto de Aprendizagem sobre Geometria. IV Colóquio de História e Tecnologia no ensino da Matemática - HTEM, UFRJ, 2008.

[15] SOUZA, Eliane R. Diniz, $\mathrm{M}^{\mathrm{a}}$ Ignez, PAULO, Rosa; M e OCHI, Fusako Hori, "A Matemática das sete peças do Tangran”. São Paulo, IME/USP, 1995.

[16] PIAGET, Jean. Aprendizagem e Conhecimento, em Piaget, P. \& Gréco, P., Aprendizagem e Conhecimento, Freitas Bastos, Rio de Janeiro, 

1974.

[17] NASCIMENTO, Antonio Sergio Alves, MENDES, Jorge Luis de Sousa, CARVALHO, Janaina Veiga, CARVALHO, C. V. A. PLOTFUNCAO e CONSTRUFIG3D: Duas ferramentas gráficas e interativas para apoio ao ensino da matemática de funções e geometria plana e espacial. Oficina realizada no Encontro Sul-Fluminense de Educação Matemática. Universidade Severino Sombra, 2005.

[18] MENDES, Jorge. L. de S., CARVALHO, C. V. A, CARVALHO, J. V, CONSTRUFIG3D: Uma Ferramenta Computacional para apoio ao ensino da Geometria Plana e Espacial. RENOTE. Revista Novas Tecnologias na Educação, v. 5, p. 1/10-10, 2007.

[19] SANTOS, Sérgio. C. Reflexões Pedagógicas Sobre o Ensino da Matemática Utilizando Ambientes Informatizados: um estudo de caso através dos sistemas computacionais CONSTRUFIG3D e SISGNE. Monografia do curso de Licenciatura em Matemática, Universidade Severino Sombra, 72 p., 2007.

[20] CARVALHO, C. C. http://www.cvac.eng.br/ConstruFig3d/construfig 3d.html. Acessado em 20 de setembro de 2007.

[21] UNESCO. O direito à educação: uma educação para todos durante toda a vida. In: Relatório Mundial sobre Educação. 2000. Portugal: Asa Editores, 2000:18.

[22] UNESCO. O direito à educação: uma educação para todos durante toda a vida. In: Relatório Mundial sobre Educação. 2000. Portugal: Asa Editores, 2000:19.

[23] SILVA, Jacqueline Neves. Tecnologia e escola. Porto Alegre, RS: Revista do Professor, 20 (79): 13-15, jul./set.2004:15. 